\title{
Competências de ensino: um estudo com professoras no contexto do jogo Traverse
}

\author{
Meire Andersan Fiorot \\ Faculdade de Ciências Aplicadas Sagrado Coração (Unilinhares) \\ Antonio Carlos Ortega \\ Universidade Federal do Espírito Santo
}

\begin{abstract}
Resumo
Esta pesquisa teve por objetivo verificar o modo de ensinar de professoras em um contexto de jogo de regras. Participaram da pesquisa quatro professoras da quarta série do ensino fundamental de uma escola particular do Espírito Santo. O procedimento de pesquisa foi organizado com uma situação de ensino, formada pelas fases de instrução e de experimentação, utilizando o jogo Traverse. O estudo contou com a colaboração de quatro crianças. Os resultados obtidos permitiram verificar que houve um predomínio de procedimentos com características negativas sendo identificadas algumas dificuldades apresentadas pelas professoras, tanto no momento de instruir quanto no de mediar. Diante dessa constatação, sugerimos uma reflexão mais ampla sobre o que têm sido oferecido aos professores em seus processos de formação docente e de formação continuada, considerando que a profissionalização requer um trabalho de tomada de consciência sobre os próprios processos de aprendizagem.
\end{abstract}

Palavras-chave: ensino; aprendizagem; psicologia genética, professores; jogo traverse.

\begin{abstract}
Teaching competences: a study with teachers in a Traverse game context. This research aimed at checking the way teachers teach in a rule game context. The participants were four teachers of the fourth grade of a private primary school in Espírito Santo State. The procedure of the research was organized within a teaching situation, build up by the stages of instruction and experiment using the Traverse game. The study had the additional participation of four children. The results showed that there was predominance of procedures with negative characteristics. The teachers presented some difficulties either at the time of instruction or mediation. Based on this observation, we suggest a wider reflection about what is being offered to the teachers in their graduation process, considering that the professionalization requires awareness of one's own learning processes.
\end{abstract}

Keywords: teaching; learning; genetic psychology; teachers; traverse game

$\mathrm{S}$ abemos que a formação de professores não é um assunto novo, nem inédito, uma vez que essa temática vem sendo abordada por meio da discussão de diferentes temas como o processo ensino-aprendizagem, a prática docente, a relação teoria-prática no cotidiano escolar, entre outros. Entretanto, tanto a escola quanto os professores estão em processo de mudança; e, em função disso e da influência das pesquisas realizadas na área, o estudo dos saberes docentes agora se apresenta com novas facetas. Tornou-se imprescindível considerar o professor como um profissional que adquire e desenvolve conhecimentos a partir da prática e no confronto com as condições da profissão.

A profissão de professor é uma prática relacional, em razão de que envolve múltiplas interações e sofre limitações diante das situações e das incertezas provenientes das reações dos outros envolvidos no processo. Desse modo, o saber ensinar não se refere apenas a uma competência cognitiva, mas a uma competência prática. Por mais que os professores saibam profundamente o conteúdo a ser ensinado, essa condição, embora necessária, não é suficiente para o trabalho pedagógico. Segundo Tardif (2005), a gestão da matéria é um desafio pedagógico, visto que o professor deve criar condições que possibilitem a aprendizagem dos alunos. O conhecimento pedagógico do conteúdo, isto é, a transposição didática, envolve as estratégias e procedimentos de transformação da matéria em função do tempo que se tem, do programa, do projeto pedagógico da escola, das características dos alunos, da sistemática de avaliação, etc. Todo esse repertório de conhecimentos pedagógicos próprios à profissão docente demonstra que não há uma "causalidade mágica entre ensinar e fazer aprender” (Tardif, 2005, p. 121). 
As rápidas transformações da sociedade requerem dos profissionais que nela atuam novas competências para atender às exigências, não só do mercado de trabalho, mas da própria sobrevivência em uma comunidade em que conhecimentos cada vez mais diversificados passam a ser necessários. Posto isso, investigar o processo de profissionalização dos professores demanda uma discussão acerca do conceito de competência. Macedo (2005) discorre sobre o tema afirmando que competências

são conjuntos de saberes, de possibilidades ou de repertórios de atuação ou de compreensão que expressam nossas múltiplas, desejadas e esperadas formas de realização profissional. Competência é o modo como fazemos convergir nossas necessidades e articulamos nossas habilidades em favor de um objetivo e solução de um problema que se expressam como desafio ou obstáculo. (p. 63-64)

O autor apóia-se na perspectiva sistêmica ${ }^{1}$ para analisar o cotidiano escolar e as competências necessárias a quem atua nesse contexto. Afirma que as situações cotidianas da sala de aula são repletas de desafios e obstáculos que exigem a articulação de habilidades visando à resolução dos problemas que se apresentam. Há, por parte dos profissionais envolvidos, um compromisso pedagógico a ser cumprido; para tanto, é necessário considerar os vários aspectos que atravessam o processo ensino-aprendizagem, os quais, na maior parte do tempo, são contraditórios. Apesar das tensões daí resultantes, não é possível excluir nenhuma das partes, em função de que estas interagem dinamicamente compondo uma totalidade. Dessa forma, antecipação e urgência, certezas e incertezas, conflitos, disputas, e outras demandas mais, fazem parte de um mesmo sistema, "e o desafio é coordenar tudo isso em favor do que foi proposto e que vale a pena realizar" (Macedo, 2005, p. 64). Com isso, o professor passa de um exclusivo transmissor de conceitos para um gestor, o que implica, além do ensino dos conceitos, o manejo da sala de aula de modo a manter a disciplina e envolver os alunos para que façam as tarefas e sejam cooperativos. Para este autor, a competência do sujeito será sempre relacional, posto que o importante é a interdependência entre os fatores que interagem em um contexto específico. Na escola, por exemplo, é preciso coordenar os diferentes fatores que interferem no processo, incluindo os que podem ser previstos e aqueles que são decididos na hora por não serem antecipáveis.

Todavia, como assinala Macedo (2005), os professores têm apontado que não se sentem competentes para administrar o tempo e o espaço das tarefas escolares. $\mathrm{O}$ autor afirma que, infelizmente, existem professores que são maus gestores; faltalhes competência relacional. De acordo com a perspectiva construtivista, a competência não é algo de inato ou hereditário que está dado previamente, como um talento ou um dom, independente de quaisquer condições ou contextos. Sendo assim, o fato de os professores não estarem preparados para gerir o processo ensino-aprendizagem não é um problema individual deles. O processo de formação docente deve possibilitar o desenvolvimento das competências necessárias para que o professor aprenda a lidar com os obstáculos e desafios presentes na realidade educacional. Para isso, é necessário um espaço e uma atitude favorável à reflexão, uma vez que a profissionalização não pode ser pensada desvinculada do processo de reflexão do sujeito sobre sua própria prática.

Em conformidade com a visão construtivista, a competência envolve tomada de consciência, o que significa que as competências não podem ser treinadas e sim desenvolvidas mediante uma atitude reflexiva. Para que os professores desenvolvam competências de ensino, precisam apropriar-se de suas ações, pelo processo de abstração reflexionante ${ }^{2}$, e não serem treinados em situações práticas planejadas. Segundo Becker (2001), "o treinamento leva o professor a assumir um fazer, uma prática, sem a compreensão, sem a teoria que lhe dá sentido" (p. 66). Essa afirmação confirma a idéia de que a transformação da educação inclui a reestruturação da formação dos professores; visto que, para alterar as relações pedagógicas existentes na sala de aula, o professor deve rever sua concepção acerca do conhecimento.

Para possibilitar o processo de desenvolvimento que fundamenta a aprendizagem e não torná-la inócua, o professor necessita saber como se constitui o conhecimento e não há nada mais distante da produção escolar do conhecimento do que o treinamento. Em lugar de treinar, é necessário criar condições, por meio de contextos de aprendizagem apropriados, para que os professores possam desenvolver competências que permitam a eles trabalhar com os diferentes modos de aprender das crianças; e, além disso, questionar, discutir, debater e propor reflexões sobre a vida na escola. Infelizmente, o tempo didático, o currículo, assim como outras questões relacionadas ao cotidiano escolar, ainda são pautados na perspectiva da pedagogia nãodiferenciada, a qual dificulta trabalhar a singularidade e o ritmo de cada criança (Macedo, 2005). Apesar disso e por isso, os professores precisam se profissionalizar e a prática reflexiva é um dos caminhos para isso.

A prática reflexiva inclui o processo de interiorização inerente à tomada de consciência (Piaget, 1977), o qual implica, progressivamente, a apropriação da ação e supõe um voltar-se para dentro de si mesmo. Desse modo, a apreensão e transformação do mundo pelo sujeito ocorrem à medida que ele apreende a si mesmo como sujeito, o que significa apreender sua prática, sua ação.

Conforme Perrenoud (1999), a competência envolve tomada de decisão, mobilização de recursos e ativação de esquemas. Assim, ser competente é saber tomar decisões, o que significa saber fazer escolhas, julgar, correr riscos, ser autônomo, conviver com aspectos opostos, superar conflitos. Ser competente também é saber mobilizar recursos; é saber movimentar-se, agir com criatividade apesar das dificuldades e obstáculos, é sair da posição de queixa ou lamento e assumir uma posição em favor de uma meta ou desejo. E, ainda, ser competente é saber ativar os esquemas de forma a administrar uma situação complexa.

Entre os esquemas necessários à prática pedagógica, um dos mais relevantes é o esquema de procedimento. Ele expressa o domínio do como fazer. Essa é uma das principais dificuldades enfrentadas pelos professores, visto que ocorrem muitas discussões teóricas, mas poucas são as oportunidades, 
durante a formação, de experimentar as situações, muitas vezes contraditórias, presentes no cotidiano escolar. Como afirma Macedo (2005), "é da falta ou insuficiência dos procedimentos em si mesmos ou em seus alunos que os professores se queixam" (p. 78). A reflexão é fundamental aqui, pois não basta saber fazer; é preciso compreender as razões da ação, já que é essa compreensão que sustenta uma prática profissional convicta, sem medos e inseguranças.

Para abordar as competências de ensino de forma mais específica, recorremos a Campos (2004) que, baseando-se nas proposições de Piaget acerca das causas do fracasso escolar, identificou as seguintes competências como necessárias ao ensino:

organizar situações de ensino centradas em ações reais e materiais (...); (...) encontrar estratégias para distribuir suas funções coletivamente, de modo a promover intercâmbios entre os alunos e destes com o professor, orientados para a necessidade de explicar, de justificar, de demonstrar as razões de uma ação (...); (...) respeitar as crenças espontâneas da criança e não desenganá-la em suas hipóteses explicativas, ainda que deformadas ou contraditórias (...); (...) mobilizar recursos de avaliação que permitam objetivar, problematizar e sistematizar o processo construtivo da criança (...); (...) planejar situações de discussão coletiva das opiniões, dos achados ou das soluções encontradas (...); (...) saber fazer perguntas. (pp. 27-28)

Para complementá-las, também recorremos às Diretrizes Curriculares Nacionais para a Formação de Professores da Educação Básica, em nível superior (Conselho Nacional de Educação/Conselho Pleno, 2002a, 2002b), que pontua um conjunto de competências as quais um professor deve possuir para atuar na educação básica. Este documento ressalta que essas competências devem ser integradas e contextualizadas por aquelas específicas, próprias de cada etapa e de cada área do conhecimento.

Relacionamos as competências necessárias aos professores da educação básica (CNE/CP, 2002a, 2002b) e as assinaladas por Campos (2004) com os estudos de Macedo (2005), Macedo, Petty e Passos (2000) e elegemos algumas competências como fundamentais ao processo de ensino. Assim, consideramos que o ensino demanda as competências em observar; planejar; utilizar a linguagem para perguntar e explicar; e, principalmente, coordenar os diversos aspectos presentes em uma situação.

Algumas pesquisas que têm como referencial teórico a perspectiva piagetiana, tais como a de Abreu (1993), Campos (2004), Fiorot (2001) e Rabioglio (1995), apontam importantes reflexões acerca do papel do professor no processo de construção do conhecimento por parte do aluno. $\mathrm{O}$ educador deve intervir propondo situações-problema para que os alunos, ao refletirem sobre elas, ampliem seus esquemas cognitivos.

Posto isso, consideramos que é necessário redefinir o lugar do professor, reposicioná-lo, o que implica, ao mesmo tempo, tirar-lhe o peso da transmissão e dar-lhe o caráter de co-responsável no processo de construção do conhecimento. Nesse sentido, a mediação deve ser vista como uma qualidade diferenciada da relação educacional.
De acordo com as proposições piagetianas sobre a origem do conhecimento, a mediação é constituída pela própria ação do sujeito. É por meio de sua atividade, tanto no plano externo quanto interno, que o sujeito coordena meios e fins e se auto-regula, o que possibilita a construção do conhecimento. Todavia, ao tratar da situação de ensino, Piaget (1976) destaca as intervenções do adulto como necessárias à aprendizagem, posto que não basta a atividade espontânea da criança na experimentação de métodos e soluções. O professor deve orientar as atividades dos alunos de modo a favorecer o avanço no conhecimento, sendo seu grande desafio pedagógico a tarefa de transformar a matéria para que os alunos possam compreendê-la e assimilá-la. Para tanto, deve organizar intervenções que provoquem a reflexão e propiciem a tomada de consciência.

Em uma dimensão relacional, os saberes acerca dos conteúdos das disciplinas não são mais condição suficiente para ensinar bem, já que "sabemos agora que o professor ensina na medida que domina os meios para mobilizar uma ação do aluno e conferir-lhe um sentido, de modo que essa ação se transforme em uma atividade de construção de conhecimento" (Campos, 2004, p. 32). O professor, em sua função, deve ensinar conjuntos complexos de conhecimentos a alunos com características diferentes, tornando-se um elemento intermediário entre o aluno e o conhecimento.

Esse modo de pensar a função mediadora do professor sustenta-se na explicação piagetiana do desenvolvimento cognitivo, considerando a estrutura do pensamento da criança e suas leis de desenvolvimento. Piaget (1974) afirma que a criança é, ao mesmo tempo, idêntica e diferente do adulto. Em termos de função, ela é idêntica, pois é um ser ativo, mas sua ação ocorre de acordo com a estrutura que caracteriza cada estádio de seu desenvolvimento. Dessa maneira, a mediação do adulto deve levar em conta a forma como a criança raciocina em cada momento de seu desenvolvimento, sabendo que a lógica da criança é diferente da lógica do adulto. Por isso, os conteúdos escolares não podem ser dados na modalidade de conferências como se faz com os adultos e sim por meio de outro procedimento de ensino, que valorize a ação do aluno, tal como a situação-problema.

Sendo assim, o papel do educador como mediador é indispensável na construção do conhecimento pela criança. Para tanto, ele deve ir além dos conhecimentos sobre os conteúdos a ensinar e estar bem informado sobre o desenvolvimento psicológico da inteligência (Piaget, 1974).

Partindo dessas considerações, o presente trabalho tem por objetivo investigar, em um contexto de jogos de regras, o modo de ensinar de professoras, analisando os procedimentos por elas utilizados para instruir e para mediar as ações de crianças no jogo Traverse.

O motivo desse trabalho justifica-se pelo fato de existirem apenas alguns estudos que utilizam jogos de regras com adultos (Barcelos, 2002; Louzada, 2003; Queiroz, 1995; Resende, 2004; Silva, 2005) sendo poucos com professores (Campos, 2004; Fiorot, 2001; Rabioglio, 1995; Teixeira, 1982), e do Traverse ser um jogo de regras pouco investigado em pesquisas empíricas com uma perspectiva construtivista (Palhares, 2003). 


\section{Método}

\section{Participantes}

Participaram da pesquisa ${ }^{3}$ quatro professoras (Amélia, Sabrina, Michele e Izabel) ${ }^{4}$ da quarta série do ensino fundamental que atuavam na docência, em média há treze anos, com idade variando entre 32 e 37 anos, todas trabalhando em uma mesma escola particular do Espírito Santo. Todas as participantes possuíam o curso de Pedagogia e pelo menos um curso de especialização na área da educação.

\section{Instrumento e procedimento}

Como instrumento de investigação foi utilizado o Traverse, que é um jogo de estratégia comercializado, no Brasil, pela Unicef. É constituído por um tabuleiro quadrado e quadriculado, com 100 casas e 32 peças, conforme a Figura 1.

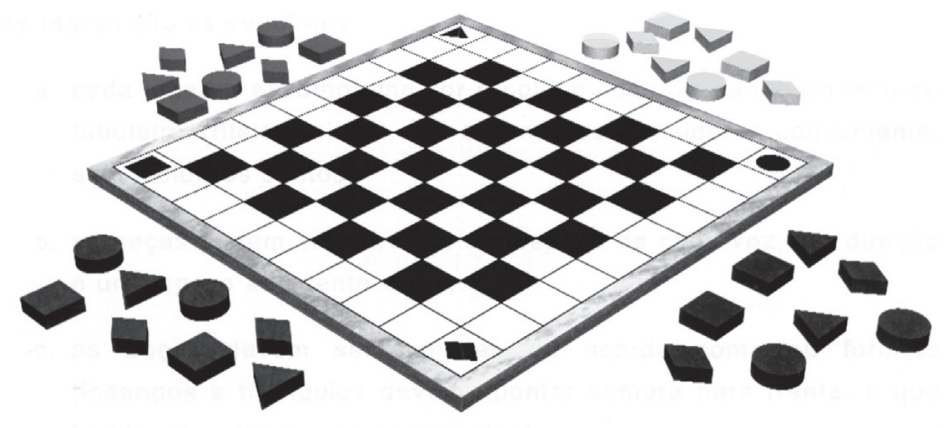

Figura 1. Tabuleiro e peças do jogo Traverse.

As peças distribuem-se em quatro cores: vermelhas, amarelas, azuis e verdes; sendo dois quadrados, dois losangos, dois triângulos e dois círculos de cada cor. Pode ser jogado, no mínimo, com dois e, no máximo, com quatro jogadores. $\mathrm{O}$ objetivo do jogo é transportar todas as peças da fileira inicial para a fileira de destino, no lado oposto do tabuleiro, o que corresponde ao significado do nome do jogo. O jogador que primeiro alcançar este objetivo é o vencedor.

Quanto ao funcionamento, podemos afirmar que a lógica contida no Traverse é coerente com a noção de sistema em Piaget $(1986)^{5}$, visto que este é constituído por um conjunto de relações interdependentes que formam uma totalidade estável, cujos elementos se modificam a partir de ações momentâneas e temporalmente sucessivas. Dito de outro modo, seu sistema integra relações espaço-temporais, visto que trabalha o deslocamento de peças em um tabuleiro, sendo a noção de espaço correspondente ao lugar dos objetos e as relações entre eles, e a noção de tempo, referente ao domínio da seqüência ou ordem das ações.

A pesquisa foi constituída por duas fases com o jogo Traverse, a de instrução e a de experimentação, e teve a colaboração de quatro crianças, alunos da quarta série do ensino fundamental, cada uma indicada por uma das professoras participantes. Antes de iniciar a fase de instrução, as professoras aprenderam a jogar o Traverse jogando contra a experimentadora e as outras participantes.

Durante a fase de instrução, cada professora foi solicitada a ensinar seu aluno colaborador a jogar o Traverse em uma sessão individual. Foi-lhes dito que deveriam ensinar o jogo às crianças, da maneira como considerassem melhor, e que jogariam duas partidas.
$\mathrm{Na}$ fase de experimentação, ocorreram quatro encontros, tendo cada um a participação de uma das professoras e de dois alunos. Cada criança participou de dois encontros, sendo que cada dupla teve uma professora como mediadora. Em cada encontro, foram jogadas duas partidas com o Traverse. A orientação dada às professoras foi a de que as crianças jogariam uma contra a outra e elas ficariam como mediadoras, intervindo do modo como considerassem mais adequado.

\section{Critérios de análise}

Foram analisados os procedimentos utilizados pela professora nas fases de instrução e mediação.

A Tabela 1 apresenta as oito categorias, definidas por suas características positivas e negativas, que serviram como indicadores para a análise das instruções e da mediação realizadas pelas professoras durante a fase de instrução.

Na fase de experimentação, analisamos a função mediadora das participantes, verificando se as professoras conferiram inicialmente se as regras e o objetivo do jogo já estavam assimilados pelos alunos. Foi também criado um contexto de reflexão, de modo a promover um progresso gradativo do nível de compreensão do aluno acerca do sistema lógico contido no jogo. A Tabela 2 contém as categorias de análise utilizadas nesta fase.

Além dos nossos registros, solicitamos às participantes que relatassem como havia sido a experiência de ensinar e a de mediar as ações da criança no jogo, incluindo as dificuldades encontradas. Com isso, pudemos analisar se as professoras tomaram consciência de suas ações, incluindo as dificuldades enfrentadas na realização da tarefa proposta. 
Tabela 1

Categorias de análise referentes à fase de instrução

\begin{tabular}{|c|c|c|}
\hline Designação geral das categorias & Características positivas & Características negativas \\
\hline $\begin{array}{l}\text { 1. Mobilização de conhecimentos } \\
\text { prévios }\end{array}$ & $\begin{array}{l}\text { Questiona os conhecimentos prévios das } \\
\text { crianças sobre os materiais que compõem o jogo } \\
\text { antes de apresentar-lhe o objetivo e as regras. }\end{array}$ & $\begin{array}{l}\text { Não se ocupa com o conhecimento anterior da } \\
\text { criança sobre formas, cores e números, ou o faz de } \\
\text { modo insuficiente detendo-se somente em alguns } \\
\text { aspectos. }\end{array}$ \\
\hline 2. Forma de apresentação do jogo & $\begin{array}{l}\text { Apresenta o jogo, por partes, descrevendo todos } \\
\text { os observáveis ou materiais que compõem o } \\
\text { jogo: tabuleiro, forma, cor e número de peças. }\end{array}$ & $\begin{array}{l}\text { Apresenta o jogo desconsiderando um ou mais } \\
\text { observáveis. }\end{array}$ \\
\hline 3. Apresentação do objetivo & Explicita o objetivo do jogo & Não esclarece o objetivo do jogo. \\
\hline 4. Apresentação das regras & Apresenta todas as regras do jogo. & $\begin{array}{l}\text { Apresenta parte das regras do jogo ou apresenta as } \\
\text { regras de modo incompleto ou confuso. }\end{array}$ \\
\hline 5. Linguagem utilizada & $\begin{array}{l}\text { Explica o objetivo e as regras utilizando um } \\
\text { vocabulário apropriado à terminologia do jogo. }\end{array}$ & $\begin{array}{l}\text { Não utiliza vocabulário adequado baseando-se mais } \\
\text { na demonstração do que na explicação. }\end{array}$ \\
\hline 6. Seqüência lógica da explicação & $\begin{array}{l}\text { Explica as regras de modo organizado de acordo com } \\
\text { a seguinte seqüência lógica: forma das peças } \Rightarrow \text { tipo } \\
\text { de movimentação } \Rightarrow \text { tipo de saltos } \Rightarrow \text { particularidade } \\
\text { do círculo } \Rightarrow \text { uso das fileiras laterais. }\end{array}$ & $\begin{array}{l}\text { Falta clareza na forma de apresentação das } \\
\text { informações devido à desorganização na exposição } \\
\text { seqüencial das regras. }\end{array}$ \\
\hline 7. Capacidade de observação & Observa as ações da criança. & $\begin{array}{l}\text { Distrai-se total ou parcialmente das ações realizadas } \\
\text { pela criança não percebendo os erros cometidos. }\end{array}$ \\
\hline 8. Modo de intervir & $\begin{array}{l}\text { Orienta as ações das crianças, corrigindo } \\
\text { deslocamentos errados, garantindo o jogar certo. }\end{array}$ & $\begin{array}{l}\text { Não intervém nas ações das crianças ou intervém } \\
\text { parcialmente permitindo a ocorrência de } \\
\text { movimentos errados. }\end{array}$ \\
\hline
\end{tabular}

Tabela 2

Categorias de análise referentes à fase de experimentação

\begin{tabular}{|c|c|c|}
\hline Designação geral das categorias & Características positivas & Características negativas \\
\hline 1. Mobilização de conhecimentos prévios & $\begin{array}{l}\text { Questiona os conhecimentos prévios das crianças } \\
\text { sobre o objetivo e as regras do jogo, verificando } \\
\text { se eles foram assimilados corretamente. }\end{array}$ & $\begin{array}{l}\text { Não se ocupa em verificar os conhecimentos } \\
\text { anteriores da criança ou faz isso de modo } \\
\text { insuficiente. }\end{array}$ \\
\hline 2. Esclarecimento de dúvidas & Esclarece as dúvidas acerca das regras do jogo. & $\begin{array}{l}\text { Não é clara no momento de sanar as dúvidas da } \\
\text { criança sobre as regras do jogo. }\end{array}$ \\
\hline 3. Capacidade de observação & Observa as ações das crianças mutuamente. & $\begin{array}{l}\text { Distrai-se total ou parcialmente das ações } \\
\text { realizadas pelas crianças não percebendo os erros } \\
\text { cometidos, ou centra a observação nas ações de } \\
\text { apenas uma das crianças. }\end{array}$ \\
\hline 4. Modo de intervir & $\begin{array}{l}\text { Faz perguntas de forma pertinente, mas não } \\
\text { "invasiva", de maneira a propiciar uma reflexão } \\
\text { sobre a ação e guiar o raciocínio sem induzir a } \\
\text { uma resposta na criança. }\end{array}$ & $\begin{array}{l}\text { Não intervém nas ações das crianças permitindo } \\
\text { a ocorrência de movimentos errados ou intervém } \\
\text { induzindo suas ações e respostas. }\end{array}$ \\
\hline
\end{tabular}




\section{Resultados e discussão}

Em se tratando da fase de instrução, verificamos que em relação à Mobilização de conhecimentos prévios (categoria 1), todas as participantes adotaram o procedimento de explorar o material do jogo com a criança investigando seus conhecimentos prévios sobre os materiais que o compõem antes de explicar seu objetivo e suas regras. Contudo, apenas Sabrina abordou os vários aspectos possíveis de serem trabalhados incluindo as diferentes características tanto das peças quanto do tabuleiro. As demais trataram apenas da investigação dos atributos das peças, sendo que nenhuma das três englobou seus três principais aspectos: cor, forma e número. Desse modo, a mobilização dos conhecimentos já existentes ocorreu de maneira insuficiente considerando as professoras Izabel, Michele e Amélia, as quais se detiveram somente em alguns dos aspectos importantes para a aprendizagem do jogo. Esse resultado teve influência direta na Forma de apresentação do jogo (categoria 2), pois a professora que explorou os conhecimentos das crianças sobre mais atributos do jogo também apresentou seus materiais em maiores detalhes.

Após a exploração do material e apresentação do jogo, passaram à Explicação do objetivo e das regras do jogo (categorias 3 e 4). Verificamos que Sabrina, Izabel e Amélia apresentaram o objetivo do jogo em momentos diferentes de suas instruções, sendo Michele a única participante que não fez referência direta a ele durante sua explicação. No que diz respeito às regras, nem todas foram mencionadas pelos participantes e, em alguns casos, o foram de modo confuso e incoerente.

Esses resultados se relacionam às dificuldades encontradas na Linguagem utilizada e na Seqüência lógica da explicação (categorias 5 e 6). Sabrina e Izabel utilizaram um vocabulário apropriado à terminologia do jogo durante a maior parte das explicações das regras e do objetivo, enquanto Amélia e Michele basearam-se mais na demonstração do que na explicação. No que se refere à seqüência lógica da explicação, para Amélia e Michele, faltou clareza na forma de apresentação das informações devido à desorganização na exposição seqüencial das regras, visto que misturaram informações sobre os tipos de saltos, com outras sobre a forma de movimentação e ainda com instruções sobre a particularidade do círculo.

Após o momento inicial de apresentação do jogo, seu objetivo e suas regras, foi jogada a primeira partida durante a qual, praticamente, não houve comentários, com exceção de Izabel, que foi fazendo observações e esclarecendo as dúvidas da criança. Durante a segunda partida, o número de intervenções foi menor, sendo em alguns casos inexistente. Ao término das partidas, as quatro professoras fizeram questionamentos sobre o que havia ocorrido durante o jogo, sendo que Sabrina, Izabel e Amélia exploraram os acontecimentos do jogo mais detidamente, investigaram mais detalhadamente o pensamento das crianças, enquanto Michele fez menos questionamentos com perguntas mais superficiais.

Ao longo das duas partidas, pudemos notar, ao analisarmos a Capacidade de observação e o Modo de intervir (categorias 7 e 8), que todas as professoras distraíam-se total ou parcialmente das ações realizadas pela criança, conseqüentemente, não intervinham nas ações das crianças ou o faziam parcialmente, permitindo a ocorrência de movimentos errados.

Em síntese, de acordo com as referidas categorias utilizadas para a análise dos procedimentos de ensino, na fase de instrução, podemos notar na Tabela 3 que, no caso de Amélia e Michele, preponderaram as características negativas, enquanto em Sabrina predominaram as positivas. No caso da professora Izabel, as características positivas e negativas distribuíram-se na mesma proporção.

Tabela 3

Análise dos procedimentos adotados durante a fase de instrução, a partir das categorias estabelecidas

\begin{tabular}{|c|c|c|c|c|}
\hline \multirow{3}{*}{ Designação geral das categorias } & \multicolumn{4}{|c|}{ Professoras participantes } \\
\hline & Amélia & Sabrina & Michele & Izabel \\
\hline & \multicolumn{4}{|c|}{ Características } \\
\hline 1. Mobilização de conhecimentos prévios & negativas & positivas & negativas & negativas \\
\hline 2. Forma de apresentação do jogo & negativas & positivas & negativas & negativas \\
\hline 3. Apresentação do objetivo & positivas & positivas & negativas & positivas \\
\hline 4. Apresentação das regras & negativas & positivas & negativas & positivas \\
\hline 5. Linguagem utilizada & negativas & positivas & negativas & positivas \\
\hline 6. Seqüência lógica da explicação & negativas & positivas & negativas & positivas \\
\hline 7. Capacidade de observação & negativas & negativas & negativas & negativas \\
\hline 8. Modo de intervir & negativas & negativas & negativas & negativas \\
\hline
\end{tabular}


$\mathrm{O}$ ato de ensinar requer o domínio sobre os processos de aprendizagem e sobre os procedimentos de ensino. Assim, ser competente no ensino exige a coordenação de diversos fatores que atravessam tanto o processo de aprendizagem como o de ensino. No entanto, constatamos, de acordo com Tardif (2005), Macedo (2005) e ainda segundo o parecer do CNE/ CP (2002a), o afastamento entre o campo da aprendizagem e o do ensino. Separação na formação que se reproduz na prática profissional, pois da mesma maneira que a aprendizagem dos professores sobre como ensinar é desvinculada de seus saberes e de uma reflexão sobre os mecanismos envolvidos em seu próprio processo de aprendizagem, quando assumem o lugar de ensino, também não conseguem se utilizar de suas experiências de aprendizagem e das experiências dos próprios alunos. Esse isolamento foi identificado em nossa pesquisa, quando verificamos as dificuldades enfrentadas pelas professoras para planejar e organizar a situação de ensino de forma a favorecer a aprendizagem das crianças.

Ao serem solicitadas a falar sobre a experiência de ensinar o jogo, as professoras tiveram a oportunidade de refletir sobre as ações realizadas e apontar, até mesmo, as dificuldades enfrentadas. Durante os diálogos estabelecidos, o tema que foi citado por todas as participantes, em menor ou maior intensidade, refere-se à dúvida quanto ao que dizer diante de algumas situações.

Sabrina, por exemplo, trata a questão da observação das ações da criança como uma dificuldade sua. A razão disso, segundo ela, foi o fato de centrar sua atenção em suas próprias ações. Em muitos momentos, não percebia os erros cometidos pelo aluno, com relação às direções do movimento de cada peça e a forma como os saltos estavam sendo realizados.

Apesar de nem todas as professoras terem abordado esta questão, nossos registros, durante esta fase da situação de ensino, confirmam que esses comentários da professora Sabrina aplicam-se às demais participantes. As professoras perderam importantes oportunidades de intervir de modo a favorecer a compreensão das regras por parte do aluno. Além disso, em muitos momentos, os alunos realizavam movimentos errados e isso não era percebido por elas. O que observamos, e que foi confirmado pelos comentários da professora Sabrina, é que a dificuldade em perceber o erro de seu aluno, neste caso, seu adversário, deveu-se, principalmente, à sua centração no seu próprio jogo e, conseqüentemente, à impossibilidade de observar as ações do outro.

$\mathrm{Na}$ fase de instrução proposta com o Traverse, verificamos que as participantes conseguiram apresentar as principais regras do jogo e esclarecer as dúvidas das crianças. Entretanto, observamos que, ao ensinar o jogo, as professoras enfrentaram diferentes graus de dificuldades, sendo que, de modo geral, as principais foram: a carência de organização e, por conseguinte, de seqüência lógica nas instruções; a limitação no uso da linguagem para dar as explicações sobre as regras e o objetivo do jogo, predominando a demonstração no tabuleiro; a insuficiência na observação das ações da criança, até mesmo, de seus erros; e a hesitação sobre os momentos de intervir. Dentre as participantes, Amélia e Izabel não relataram nenhuma destas dificuldades, Michele falou sobre duas delas, mas não aprofundou a discussão e não se implicou na questão. Somente Sabrina tomou consciência de suas dificuldades, a partir de uma reflexão sobre elas.

Brow, citada por Montero (1996), afirma que tomar consciência das próprias dificuldades enfrentadas para compreender uma tarefa é tão importante quanto conhecer algo. Assim, é importante reconhecer que não se sabe, já que é este saber sobre o não saber que permite superar as dificuldades. Essa idéia confirma as afirmações piagetianas que apontam que o progresso do sujeito ocorre à medida que ele apreende sua própria ação, o que significa tomar consciência dos mecanismos que a regulam.

Todavia, tomar consciência de certas ações não é tão simples, posto que esse processo traria "à luz comportamentos e atitudes pouco defensáveis em relação ao que se pensa ou gostaria de ser" (Perrenoud, 2001, p. 172). No caso do jogo, significa defrontar-se com os próprios erros, e, muitas vezes, com o fracasso no alcance dos objetivos. Portanto, em um contexto de formação, seria necessário criar situações que privilegiassem a utilização de alguns mecanismos, tais como a reflexão sobre a prática e a observação mútua, capazes de favorecer a tomada de consciência.

Após a análise dos resultados da fase de instrução, passamos à fase de experimentação da situação de ensino, na qual as professoras ficaram como mediadoras do jogo das crianças, intervindo quando achassem necessário. A Tabela 4 apresenta a síntese desta análise.

Tabela 4

Análise dos procedimentos adotados durante a fase de experimentação, a partir das categorias estabelecidas

\begin{tabular}{|c|c|c|c|c|}
\hline \multirow{2}{*}{ Designação geral das categorias } & Amélia & Sabrina & Michele & Izabel \\
\hline & \multicolumn{4}{|c|}{ Características } \\
\hline 1. Mobilização de conhecimentos prévios & negativas & negativas & negativas & negativas \\
\hline 2. Esclarecimento de dúvidas & positivas & positivas & negativas & positivas \\
\hline 3. Capacidade de observação & negativas & negativas & negativas & negativas \\
\hline 4. Modo de intervir & negativas & negativas & negativas & negativas \\
\hline
\end{tabular}


Verificamos que, com exceção da categoria 2, o tipo de mediação adotado por todas as professoras foi marcado por características negativas. Uma análise mais minuciosa demonstrou que com relação à Mobilização de conhecimentos prévios (categoria 1), apesar de todas apresentarem características negativas, houve diferenças entre os procedimentos adotados. Amélia e Sabrina perguntaram às crianças se elas se lembravam do modo de jogar, sem, no entanto, se ocuparem de verificar o que elas efetivamente haviam assimilado. Izabel, por sua vez, solicitou às crianças que demonstrassem a movimentação das peças sem, contudo, verificar a compreensão dos tipos de saltos possíveis. Michele não apresentou nenhuma pergunta antes de iniciar o jogo. Com isso, há uma flutuação entre a ausência de verificação dos conhecimentos prévios e a mobilização insuficiente destes.

Segundo Meirieu (2005), para ensinar, é preciso apoiarse naquilo que o sujeito já sabe, considerando as aquisições anteriores dos alunos. Esta proposta embasa-se na proposta piagetiana a qual ressalta que a aprendizagem de um conceito é interdependente ao desenvolvimento das estruturas cognitivas. Em outras palavras, a aprendizagem de algo novo ocorre a partir das estruturas já existentes sendo que toda nova aprendizagem contribui para modificar estas estruturas. Logo, mobilizar os conhecimentos prévios das crianças para, a partir deles, dar continuidade ao trabalho ou retomar pontos específicos que carecem de esclarecimento é uma competência importante a quem ocupa o lugar de mediador diante daquele que constrói seu conhecimento.

Com relação ao Esclarecimento de dúvidas (categoria 2), com exceção de Michele, as professoras respondiam às dúvidas das crianças esclarecendo situações específicas do jogo.

Duas dificuldades observadas na fase de experimentação da situação de ensino e confirmadas pelos comentários das participantes referem-se à Capacidade de observação das ações das crianças e a Forma de intervir (categorias 3 e 4). As professoras mencionaram suas dificuldades em observar as jogadas das crianças, alegando algumas causas, tais como: a rapidez com que elas jogavam, o que deixava as professoras perdidas; e o fato de elas, professoras, concentrarem-se em um momento do jogo e, com isso, se descuidarem das ações subseqüentes, não percebendo os erros que podiam estar sendo cometidos.

Com relação à intervenção durante a partida, Amélia e Michele afirmaram que preferiam não intervir durante o jogo, deixando que os próprios alunos percebessem as outras possibilidades. Sabrina e Izabel, por outro lado, disseram ter dúvidas sobre o momento de intervir e sobre o que dizer. Assim, a principal questão discutida nesta fase referiu-se ao tipo de mediação a ser adotado. A professora Sabrina refletiu sobre suas ações, tomando consciência de suas dificuldades no processo e falando amplamente sobre isso.

A análise apresentada até aqui demonstra as restrições na qualidade das intervenções adotadas durante a mediação. As participantes careciam de convicção sobre como agir e, com exceção da professora Sabrina, não tomavam consciência de suas dificuldades no processo. Em função dos nossos objetivos, a metodologia da pesquisa não possibilitou um trabalho de intervenção com as professoras, em situações de ensino, que pudesse contribuir para o progresso das competências de instrução e de mediação, já que nos detivemos em analisar os procedimentos que as professoras utilizaram para ensinar uma criança a jogar.

Quanto ao tipo de mediação adotada, consideramos que as dificuldades observadas estão atreladas, em grande parte, a um conflito subjacente a suas concepções sobre o processo ensino-aprendizagem. Pudemos verificar as contradições nos discursos das professoras que ora apontavam os problemas enfrentados pelos docentes em sua formação e na gestão das atividades acadêmicas, os quais interferem no processo de aprendizagem dos alunos, ora apontavam os alunos como os responsáveis por suas dificuldades. Essa contradição apareceu quando as professoras separavam a ação da criança da ação do professor, enfatizando uma ou outra, como se fossem independentes. Sabrina, por exemplo, indicou as seguintes possibilidades: ou calar-se e deixar o aluno jogar sozinho, ou dar palpites, apontando como o aluno deveria jogar. Essa dicotomia relaciona-se à concepção epistemológica apriorista e a empirista; e, conseqüente e respectivamente, a dois modelos pedagógicos. $\mathrm{O}$ primeiro modelo refere-se a uma pedagogia não-diretiva e o segundo a uma pedagogia diretiva (Becker, 2001). Para superar esse impasse, seria preciso assumir uma terceira forma de intervir, considerando, conforme Campos (2004), que a função do professor é a de mediação, no sentido de uma função transitiva entre dois elementos; neste caso, o aluno e o jogo - seu objeto de conhecimento. Com base nessa autora, podemos afirmar que o papel do professor, neste contexto de jogo, deveria ser o de propor questionamentos, contra-argumentações e outras intervenções que provocassem a reflexão e, por conseguinte, a revisão das ações apressadas e, muitas vezes, incorretas ou prejudiciais ao futuro do jogo. Desse modo, a competência de ensino, em especial, a competência na função mediadora relaciona-se a uma concepção interdependente da construção do conhecimento.

Segundo Perrenoud (1999), a competência envolve tomada de decisão, mobilização de recursos e ativação de esquemas. Esses três aspectos da competência foram exigidos na situação de ensino que organizamos, posto que as professoras precisavam fazer escolhas sobre o momento de intervir e sobre como fazêlo; e, considerando a experiência de aprendizagem vivida, serem autônomas inventando novos procedimentos adequados à situação específica de ensinar crianças. Além disso, deviam mobilizar recursos e serem criativas para atingir o objetivo proposto; e, ainda, diante da situação complexa proposta pelo ensino do jogo, necessitavam ativar esquemas, principalmente o esquema de procedimento, isto é, o como fazer.

Para analisar mais detalhadamente o esquema de procedimento, retomamos as competências de ensino identificadas por Campos (2004) e aquelas destacadas do documento das Diretrizes Curriculares Nacionais para a Formação de Professores da Educação Básica, em nível superior 
(CNE/CP, 2002a, 2002b). Com base nelas, e na particularidade do nosso experimento com o Traverse, elegemos as seguintes competências: observar as ações; planejar a situação; utilizar a linguagem de modo a explicar e fazer perguntas adequadamente; e, coordenar diferentes aspectos de uma situação. Verificamos que os procedimentos necessários ao ensino do Traverse demandam essas competências.

Sendo assim, a presença das características positivas que definem cada categoria indicam as competências a ela associadas, o que nos levou a verificar que, dentre essas competências citadas, algumas, indispensáveis ao ensino do referido jogo, tiveram seu aparecimento limitado nos procedimentos adotados por algumas das participantes, haja vista a predominância de características negativas nesses procedimentos (Tabelas 3 e 4). Constatamos que o uso da linguagem, para explicar e perguntar, foi influenciado pela dificuldade em planejar a seqüência da instrução, considerando o melhor encadeamento das informações. Essa dificuldade interferiu em diversos aspectos, posto que expor as regras do jogo com clareza demanda organizálas no tempo, considerando sua duração e ordem de sucessão. Ensinar o jogo exige algumas ponderações. Quanto tempo dispensar para fazer um levantamento prévio das informações? Quanto tempo dedicar às instruções sobre as regras? Qual a melhor ordem para apresentar as informações? O que é melhor explicar antes, de modo a facilitar o que vem depois? Como agrupar as diversas informações que precisam ser dadas? Amélia e Michele tiveram dificuldades em organizar suas explicações de maneira coerente a fim de tornar a instrução clara para as crianças. Além da carência dessa competência em relação às duas professoras, a principal dificuldade refere-se à competência em observar e, mais intensamente, em coordenar a observação das diferentes ações simultaneamente. Essas duas competências dão sustentação aos procedimentos analisados pelas categorias Capacidade de observação e Modo de intervir as quais foram marcadas por características negativas nas duas fases da situação de ensino e em todas as participantes.

O modo como se ensina é tão importante quanto o que se ensina. Contudo, a falta de domínio sobre os esquemas de procedimento, que expressam o como fazer, ou competência prática, é um dos problemas do ensino. Esse problema deve ser analisado a partir do contexto de formação docente, pois se o professor constrói seus saberes durante seu percurso de formação, este deve oferecer situações de aprendizagem significativas. Se o professor tem apresentado dificuldades em dominar os procedimentos de ensino, deve-se rever o modo como a formação tem ocorrido, visto que o saber sobre o conteúdo, mesmo que importante, não é suficiente para a eficácia do ensino. Como assinalam Damasceno e Cória-Sabini (2003), “o professor bem-sucedido é aquele que reflete sobre suas ações, repensa os fundamentos teóricos de sua prática, bem como seus sucessos e fracassos, e toma isso como base para alterar o ensino" (p. 244).

Assim, se considerarmos que a dimensão prática ou procedimental não pode ser separada da dimensão compreensiva ou explicativa, a formação docente deve propor situações nas quais a prática e a reflexão possam ser tratadas de modo recíproco.

\section{Considerações finais}

Os resultados apresentados demonstraram as dificuldades enfrentadas pelas professoras em observar as ações de diferentes jogadores durante o Jogo Traverse. Diante disso, nos perguntamos: como é possível ensinar se o professor tem dificuldades para observar e para coordenar as diversas exigências que concorrem no contexto de aprendizagem? Se a mediação do professor, na relação entre o aluno e o objeto de conhecimento, requer a competência em observar e coordenar ações no espaço e no tempo, como exercer essa função mediadora na carência desta competência? Será que os cursos de formação ou a formação continuada dos professores estão propiciando o desenvolvimento destas competências? Quais são as situações práticas, durante a formação docente, que possibilitam aos professores desenvolverem as competências mediadoras?

Decorre destes questionamentos a necessidade de repensar a metodologia adotada na formação com vistas a propiciar situações de aprendizagem baseadas em situações-problema ou no desenvolvimento de projetos que se caracterizem em situações comunicativas e co-participativas entre alunos, futuros professores e agentes formadores.

O contexto educacional problematiza, desequilibra, perturba, provoca tensões variadas. Por isso, diante desta realidade, o desafio do professor é ir além dos conteúdos e programas, é organizar e gerir situações de aprendizagem levando em conta os diferentes ritmos, características e motivações dos alunos. As relações estabelecidas entre as situações vividas no jogo e as situações vividas na prática pedagógica podem favorecer a reflexão sobre diferentes aspectos que limitam a atuação dos professores e possibilitar a construção de novas formas de ensinar, condizentes com as novas exigências educacionais.

Consideramos que um dos caminhos a ser percorrido pelo professor nesse processo de mudança educacional, que requer uma adaptação às novas condições socioculturais, é em direção a uma reflexão que desencadeie a tomada de consciência das relações entre as práticas de ensino e o modo como o conhecimento é construído. Para refletir sobre a construção do conhecimento, é importante que os educadores considerem os próprios mecanismos internos que lhes possibilitam a elaboração pessoal dos elementos da realidade. É fundamental refletir sobre os próprios processos de construção do conhecimento, sobre os recursos que são mobilizados nesse processo, sobre as dificuldades encontradas durante a atividade construtiva. Defrontar-se com a sua própria aprendizagem e as dificuldades envolvidas nesse processo tornará possível a organização e o planejamento de uma prática de ensino mais consciente e, por conseguinte, orientada para o que se quer que a criança se torne. O que supomos é que a construção de competências de ensino requer uma análise sobre si mesmo, envolvendo uma prática reflexiva e a tomada de consciência dos próprios processos de aprendizagem e das dificuldades vividas nesse processo.

Ratificamos essa proposição com as idéias de Perrenoud 
(2001), quando o autor afirma que é pela tomada de consciência que o professor será conduzido à lucidez perante a sua prática profissional. Para ele, uma das estratégias possíveis na formação profissional deve ser a de favorecer a tomada de consciência e a passagem de certas ações ao controle de conhecimentos procedimentais. Se o professor não toma consciência de suas dificuldades, de suas limitações em sua prática profissional, ou melhor, se ele não consegue compreender a razão de suas ações, não haverá progressos ou melhoria no processo.

Consideramos que é necessário arriscar a travessia, arriscar novos caminhos, com todos os perigos que ela possa ter. Consideramos ainda que o desenvolvimento de competências implica a tomada de consciência das próprias potencialidades e limitações, e que a identificação disso favorecerá o processo formativo. Alguns autores já discutidos ao longo desse trabalho têm se dedicado ao estudo dessas questões; esperamos que nosso trabalho seja útil para o avanço das discussões na área e uma abertura para novos espaços de construção.

\section{Referências}

Abreu, A. R. (1993). O jogo de regras no contexto escolar: uma análise na perspectiva construtivista. Dissertação de Mestrado não-publicada, Universidade de São Paulo, São Paulo.

Barcelos, S. A. (2002). Avaliação do déficit cognitivo de alcoolistas utilizando o jogo da senha em uma abordagem microgenética. Dissertação de Mestrado não-publicada, Universidade Federal do Espírito Santo, Vitória.

Becker, F. (2001). Educação e construção do conhecimento. Porto Alegre: Artmed.

Campos, M. C. R. M. (2004). Formação docente em oficinas de jogos: indicadores da função mediadora. Tese de Doutorado não-publicada, Universidade de São Paulo, São Paulo.

Conselho Nacional de Educação/Conselho Pleno, Ministério da Educação, Brasil. (2002a). Parecer CNE/CP 9/2001. Diário Oficial da União, Brasília, 18 de janeiro de 2002, Seção 1, p. 31; disponível em: http://portal.mec.gov.br/cne/ arquivos/pdf/009.pdf.

Conselho Nacional de Educação/Conselho Pleno, Ministério da Educação, Brasil. (2002b). Resolução CNE/CP 1/2002. Diário Oficial da União, Brasília, 9 de abril de 2002, Seção 1, p. 31; disponível em: http://portal.mec.gov.br/cne/ arquivos/pdf/rcp01_02.pdf.

Damasceno, S. A. N., \& Cória-Sabini, M. A. (2003). Ensinar e aprender: saberes e práticas de professores de anatomia humana. Psicopedagogia, 20(63), 243-254.

Fiorot, M. A. (2001). Como aprendem os que ensinam? Aprendizagem e jogos de regras em uma perspectiva construtivista. Dissertação de Mestrado nãopublicada, Universidade Federal do Espírito Santo, Vitória.

Fiorot, M. A. (2006). Como aprendem os que ensinam e como ensinam os que aprendem? Um estudo com professoras no contexto do jogo Traverse.
Tese de Doutorado não-publicada, Universidade Federal do Espírito Santo, Vitória.

Louzada, E. G. (2003). O jogo da senha como possivel instrumento avaliador do distúrbio cognitivo após cirurgia cardíaca. Dissertação de Mestrado nãopublicada, Universidade Federal do Espírito Santo, Vitória.

Macedo, L. (2005). Ensaios pedagógicos: como construir uma escola para todos? Porto Alegre: Artmed.

Macedo, L., Petty, A. L. S., \& Passos, N. C. (2000). Aprender com jogos e situações-problema. Porto Alegre: Artes Médicas.

Meirieu, P. (2005). O cotidiano da escola e da sala de aula: o fazer e o compreender. Porto Alegre: Artmed.

Montero, M. L. (1996). Comportamento do professor e os resultados da aprendizagem: análise de algumas relações. In C. Coll, J. E. Palacios, \& A. Marchesi (Orgs.), Desenvolvimento psicológico e educação (Vol. 2, pp. 222-243). Porto Alegre: Artes Médicas.

Palhares, O. (2003). Análise de processos cognitivos em crianças no jogo Traverse. Dissertação de Mestrado não-publicada, Universidade Estadual de Campinas.

Perrenoud, P. (1999). Construir as competências desde a escola. Porto Alegre: Artmed.

Perrenoud, P. (2001). O trabalho sobre o habitus na formação de professores: análise das práticas e tomada de consciência. In P. Perrenoud, L. Paquay, M. Altet, \& É. Charlier (Orgs.), Formando professores profissionais. Quais estratégias? Quais competências? (pp. 161-184). Porto Alegre: Artmed.

Piaget, J. (1974). Fundamentos científicos para a educação do amanhã. In J. Piaget, L. Fernig, J. A. Perkins, T. Lemaresquier, G. C. Breis, E. Faure, H. Passow, \& L. B. Pearson (Orgs.), Educar para o futuro (pp. 9-33). Rio de Janeiro: Fundação Getúlio Vargas.

Piaget, J. (1976). Psicologia e Pedagogia. Rio de Janeiro: Forense Universitária.

Piaget, J. (1977). A tomada de consciência. São Paulo: Melhoramentos/Edusp.

Piaget, J. (1986). O possível e o necessário: evolução dos necessários na criança (Vol. 2). Porto Alegre: Artes Médicas.

Queiroz, S. S. de. (1995). Tipificação de erros em um jogo de regras: uma abordagem construtivista. Dissertação de Mestrado não-publicada, Universidade Federal do Espírito Santo, Vitória.

Rabioglio, M. B. (1995). Jogar, um jeito de aprender: análise do pega-varetas e da relação jogo-escola. Dissertação de Mestrado não-publicada, Universidade de São Paulo, São Paulo.

Resende, A. (2004). Área profissional e processo da tomada de consciência: análise microgenética do jogo Torre de Hanói. Dissertação de Mestrado não-publicada, Universidade Federal do Espírito Santo, Vitória.

Silva, S. T. (2005). Desenvolvimento de estratégias cognitivas implicadas na aprendizagem de uma língua estrangeira no contexto de oficinas de jogos. Dissertação de Mestrado não-publicada, Universidade Federal do Espírito Santo, Vitória.

Tardif, M. (2005). Saberes docentes e formação profissional. Petrópolis: Vozes.

Teixeira, L. R. M. (1982). Permutação, quantificação de probabilidades e Torre de Hanói: análise comparativa em escolares de segundo grau. Dissertação de Mestrado não-publicada, Universidade de São Paulo, São Paulo. 
${ }^{1}$ Nesta perspectiva, considera-se "cada parte em relação ao todo, as partes entre si e o próprio todo de um modo interdependente e indissociável" (Macedo, 2005, p. 64).

${ }^{2}$ A abstração reflexionante, segundo Piaget (1955/1977), baseia-se nas coordenações das ações do próprio sujeito e possui dois aspectos complementares, o reflexionamento e a reflexão. No primeiro há uma projeção para um plano superior daquilo que é retirado de um patamar inferior; no segundo, ocorre a reconstrução e reorganização no novo plano daquilo que foi extraído do primeiro. Para o autor, a abstração reflexionante é um dos motores do desenvolvimento cognitivo, visto que cada novo patamar exige uma reconstrução do que foi projetado a partir do precedente. Há um processo em espiral com uma alternância ininterrupta de reflexionamentos e reflexões, em direção a domínios cada vez mais amplos, sem fim e sem começo absoluto.

${ }^{3}$ A participação foi formalizada mediante assinatura do Termo de Consentimento), elaborado segundo normas estabelecidas pelo Ministério da Saúde e pela Resolução nº 016/2000 do Conselho Federal de Psicologia, tendo o projeto sido aprovado pelo Comitê de Ética em Pesquisa do Programa de Pós-Graduação em Psicologia da UFES.

${ }^{4}$ Os nomes das participantes são fictícios.

${ }^{5}$ Para o autor "um sistema [...] é um conjunto de relações interdependentes que constituem uma totalidade com propriedades estáveis, independentemente das variações possíveis de seus elementos. Um sistema é, pois, suscetível de funcionamento sob a forma de ações ou operações momentâneas e (temporalmente) sucessivas que modificam os elementos. Comporta, por outro lado, uma 'estrutura' enquanto conjunto intemporal das transformações possíveis que respeitam as características de sua totalidade” (Piaget, 1986, p. 44).

Meire Andersan Fiorot, doutora em psicologia pela Universidade Federal do Espírito Santo, é coordenadora e professora no Curso de Graduação em Psicologia da Faculdade de Ciências Aplicadas Sagrado Coração Unilinhares. Endereço para correspondência: Rua Governador Henrique Coutinho, 96 (Conceição); Linhares, ES; CEP: 29900-470. Tel. (27) 2103-7239. Fax: (27) 2103-7200. E-mail: meireaf@unilinhares.net Antonio Carlos Ortega, doutor em psicologia do desenvolvimento pela Fundação Getúlio Vargas (RJ), é professor no Programa de Pós-Graduação em Psicologia da Universidade Federal do Espírito Santo - UFES. E-mail: acortega@terra.com.br 